\title{
Comparison of Vertical Parameters in Correction of Deep Bite Using ANS Implant And Utility Intrusion Arch
}

\author{
${ }^{1}$ Dr Adil Arora, ${ }^{2}$ Dr Shilpi S Garg, ${ }^{3}$ Dr A.Radhika Reddy \\ ${ }^{I} P G$ Student Orthodontics, $2 P G$ Student Orthodontics, 3Professor Orthodontics \\ ${ }^{1,2,3}$ MM College Of Dental Sciences And Research, MMU , Mullana
}

\begin{abstract}
Objective: We have designed this study so as to compare the vertical parameters in the utility arch and a miniimplant treatment groups.

Materials \& Methods: 12subjects were enrolled in the study and were distributed in two groups. After the initiation of the mechanics all the patients were constantly monitored and the force levels repeatedly checked by Dontrix gauge. Various cephalometric parameters were also checked for difference.

Results: The results show that the vertical parametres i.e. Jarabak ratio, SnGoGn, Y axis and FMA are insignificant in both the utility and implant group. Although, there was significant increase in occlusal cant and occlusal plane to palatal plane in utility group than in implant group in our study. Conclusion: Mini-implants were more efficient in reducing the overbite when compared to utility arches without any significant changes in vertical parameters.
\end{abstract}

\section{Introduction}

Deep bite, known to be one of the most common and the most deleterious malocclusion, affects the future health of the masticatory apparatus and the dental units. Coined by Edward Angle, it is basically a misalignment or incorrect relation between the teeth of the two dental arches when they approach each other as the jaws close. A complex orthodontic problem, a deep bite, or an overbite, may involve a group of teeth or the entire dentition, alveolar bone, of maxillary and mandibular basal bones, and/or soft tissue of the face. Certain complications of deep bite can be, temporomandibular joint disorders, unacceptable facial aesthetics, attrition of incisors, spacing of maxillary incisors, clenching of teeth, jaw stiffness, head ache and ringing in ears.

The management of this problem demands a careful diagnostic analysis, treatment plan, and selection of appropriate treatment therapy. Further, the choice of treatment depends on several factors, like upper incisor display on rest and smile, inter-occlusal space, and vertical dimension.Corrections to this problem can be made by the intrusion of anterior teeth, extrusion of posterior teeth or a combination of both. The appliances for incisor intrusion include utility arch by Ricketts, Burstone intrusion arch, Connecticut intrusion arch, and J-hook headgear. ${ }^{4}$ Also, recently, many authors have demonstrated the use of mini implants and have reported statistically significant amounts of incisor intrusion with them. ${ }^{4,,,}$,

Despite the advantages and quick improvements with these treatment options, disadvantages prevail. The intrusion of incisors, though a stable correction, root resorption can occur. ${ }^{\text {vii }}$ Other disadvantages include extrusion and tipping of posterior teeth, complex wire bending and patient co-operation.,

As presented in literature and the current dilemma prevailing over this issue, we have designed this study so as to compare the vertical parameters in correction of deep bite using the two mechanics, the utility arch and a mini-implant.

\section{Patients}

12subjects were enrolled in the study and were distributed in two groups, 1 and 2 of 6 subjects each. In Group 1, intrusion was carried with the help of Rickett's intrusion utility arch reinforced by transpalatal arches.

In Group 2, titanium mini-implants, (S.K. Surgicals) were used. Forces were measured using Dontrix gauge.

\section{Inclusion criteria}

To include the patients in this study, the following criteria were considered:

- Patients with more than $60 \%$ overbite

- Age limit 16-25 years past their pubertal growth status

- Patients with average FMA $\left(25^{\circ} \pm 5^{\circ}\right)$

- Fully erupted maxillary incisors and mandibular incisors

- Patients who have not undergone any previous orthodontic treatment 


\section{Exclusion criteria}

The patients with the following criteria were not included in this study:

- Patients who required extrusion of posteriors

- Root canal treated anterior teeth

- Cranio facial syndromes

- Individuals with history of systemic diseases.

Materials

The materials used for this study were; Utility Arch $(0.018 " \times 0.025$ " SS $)$ for 4 months. Self tapping titanium mini implant (S.K.Surgicals) of $1.3 \mathrm{~mm}$ diameter and $6 \mathrm{~mm}$ length with 0.018 " $\times 0.025$ " SS base archwire, Niti coil springs (Prime Ortho) of $9 \mathrm{~mm}$ in length and Lateral cephalograms before and after intrusion for 4 months.

\section{Methods}

\section{Cephalometric Readings:}

After the initiation of the mechanics all the patients were constantly monitored and the force levels repeatedly checked. A force level of $40 \mathrm{~g}$ was given in both utility arch and ANS implant group. The force was measured by Dontrix gauge. Post treatment records were repeated after 4 months (Lateral cephalograms and study casts).

The cephalometric parameters that were taken in this study are:

- Jaraback ratio

- $\quad$ Y-axis

- $\quad$ FMA

- Basal Plane Angle

- $\quad$ Sn-(Go-Gn)

- Palatal Plane-Occlusal Plane

- Occlusal Plane-Mandibular Plane

- Occlusal CANT

\section{Statistical Analysis}

Analysis of the data was done by using both descriptive and inferential statistics. Student unpaired ttest and paired t- test was used to find out the mean and standard deviation (SD) within the group and inter group. All these calculations were done on the software SPSS 17.0 and $p \leq 0.05$ was considered significant.

\section{Results}

We have compared the pre and post treatment variables, mentioned above, for both treatment options, the utility arch and the mini-implants.

The results show that the vertical parametres i.e. Jarabak ratio, SnGoGn, Y axis and FMA are insignificant in both the utility and implant group, as there was no loss of vertical anchorage in former group due to stabilization of molars by TPA. And in latter, there was no anchorage support from molars. (Fig. 1) There was significant increase in occlusal cant and occlusal plane to palatal plane in utility group than in implant group in our study. (Fig 2 and Fig 3)

Overall, the ANS implant treatment group has depicted a better improvement in the variables, compared to the utility arch treatment group. (Fig. 4 and Fig. 5)

\section{Discussion}

Correction of deep overbite is one of the fundamental goals of orthodontic treatment. Tooth intrusion, aimed at correcting an exaggerated overbite or an anterior open bite, poses a considerable mechanical challenge, in presence of difficulty in controlling undesirable movements of the anchorage units.

Charles Burstone has described that every patient with deep bite requires a comprehensive treatment plan which establishes whether the deep bite should be corrected by extrusion of posterior teeth; inhibition of eruption of anterior teeth or; genuine intrusion of anterior teeth. This decision is is taken as to where the clinician desires to place the occlusal plane, the amount of mandibular growth anticipated and the vertical dimension desired at the end of the treatment. To correct deep bite, especially in growing patients, extrusion of posterior teeth is commonly used, but it cannot be used in vertical growers and in adults. ${ }^{13}$

Over the last few years, development of mini-implants has enabled efficient anchorage, requiring no tooth support and with no esthetic compromise. Also, patient cooperation is not a limiting factor in these cases. ${ }^{12}$ Many reports have indicated the clinical efficiency of mini-implants in providing sufficient anchorage against 
orthodontic forces., , , , , , Since intrusive forces are applied via mini implants (TADs), molars are not strained like conventional or segmental arch mechanics in which a tip back bend is given. Therefore, there is no effect on posterior segments of the dentition.

Here, in this study we have compared the two treatment modalitites for deep bite malocclusion, the utility arch and the ANS mini implant. We have observed that the vertical parametres i.e. Jarabak ratio, SnGoGn, Y axis ,FMA are insignificant in both the utility and implant group, as there was no loss of vertical anchorage in former group due to stabilization of molars by TPA. And in latter, there was no anchorage support from molars.

The study is supported by Ozsoy OP et. Al. in which Omur Polat-Ozsoy who reported $1.92 \mathrm{~mm}$ of upper incisor intrusion in 4.5 months, and US Krishna Nayak etal showed, the mean true incisor intrusion achieved with mini-implants was $3.29 \mathrm{~mm}$ and with utility arches it was $1.29 \mathrm{~mm}$ with insignificant vertical parameters.

There was significant increase in occlusal cant and occlusal plane to palatal plane in utility group than in implant group in our study. Similar results were seen in Krishnanayak et. Al. in which there was extrusion of molars in the utility group. This increase in the occlusal plane to palatal plane value was large because of distal tipping of the first maxillary molars, in utility arch group.

Intrusive mechanics in the implant group was employed on continuous arches and the intrusive force generated by the NiTi coil springs not just intruded the anterior teeth but also corrected the occlusal cant.

However more critical evaluation of these force systems in larger sample size, over a longer period of time would be required to validate these observations. Further studies should investigate the post-treatment stability and molar position of these techniques which is not mentioned in our study.

\section{Conclusion}

Both the mini-implant and intrusion utility arch were useful in intrusion of maxillary incisors.

The mini-implant technique for true incisor intrusion can be considered superior to the use of conventional utility arches. Mini-implants were more efficient in reducing the overbite when compared to utility arches without any significant changes in vertical parameters.

\section{Figure legends}

Fig.1: Intergroup comparison of all variables. Showing Basal Plane Angle significantly different among the two groups

Fig. 2: Comparison of different Pre and Post treatment variables in the Utility Arch Group. The Palatial PlaneOcclusion Plane and Occlusion Plane-Mandibular Plane are significantly different pre and post treatment

Fig.3: Comparison of different Pre and Post treatment variables in the ANS implant Group. None of the variables are significantly different pre and post treatment

Fig. 4: Pre and post intrusion photograph of the utility arch treatment

Fig. 5: Pre and post intrusion photograph of the mini implant treatment

\section{References}

[1]. Amarnath BC, Prashant CSDharma RM. Clinical Overview of Deep Bite Management. IJCD 2010; 1(2): $30-33$.

[2]. Gruenbaum, Tamar. Famous Figures in Dentistry Mouth . JASDA 2010; 30(1):18.

[3]. Sreedhar CVVR, Baratram S. Deep overbite-A review (Deep bite, Deep overbite, Excessive overbite). Annals and excesses of dentistry. 2009; 1(1): 8-25.

[4]. Jain RK, Kumar SR, Manjula WS. Comparison of Intrusion Effects on Maxillary Incisors Among Mini Implant Anchorage, J-Hook Headgear and Utility Arch. Journal of Clinical and Diagnostic Research. 2014, 8(7): ZC21-ZC24.

[5]. Sonnesen, Svensson. Temporomandibular disorders and psychological status in adult patients with a deep bite. Eur J Orthod. 2008; 30(6): 621-29.

[6]. Aydogdu E, Ozsoy OP. Effects of mandibular incisor intrusion obtained using a conventional utility arch vs bone anchorage. Angle Orthodontist. 2011; 81(5): 767-775.

[7]. Bhat M, Ninan VK, Somaiah S, Madhur V. Evaluation of apical root resorption in orthodontic patients with maxillary anterior intrusion using utility arches and mini screws: A comparative clinical trial. APOS Trends in Orthodontics. 2014; 4(1): 3-8.

[8]. Saxena R, Kumar PS, Upadhyay M, Naik V. A clinical evaluation of Orthodontic Mini-implants as intraoral anchorage for the intrusion of maxillary anterior teeth. World J Orthod. 2010; 11(4): 346-51.

[9]. Omur Polat-Ozsoy, Ayca Arman-Ozcirpici and Firdevs Veziroglu. Miniscrews for Upper Incisor intrusion. Eur J Orthod. 2009; 31(4): 412-16

[10]. Upadhyay M, Nagaraj K, Yadav S, Saxena R. .Mini-implants for En masse Intrusion of Maxillary anterior teeth in a severe Class II division 2 malocclusion. J Orthod. 2008; 35(2):79-89.

[11]. Hidetake Ohnishi, Takakazu Yagi, Yoshitaka Yasuda, Kenji Takada. A Mini-Implant for Orthodontic Anchorage in a Deep Overbite Case. Angle Orthod. 2005; 75: 444-52.

[12]. Araujo TM, Nascimento MHA, Franco FCM, Bittencourt MAV. Tooth intrusion using mini-implants. Dental Press J. Orthod. 2008; 13(5): 36-48.

[13]. Burstone CJ. Deep overbite correction by intrusion. Am J Orthod. 1977; 72:1- 22.

[14]. Umemori M, Sugawara J, Mitani H, Nagasaka H, Kawamura H. Skeletal anchorage system for open-bite correction. Am J Orthod Dentofacial Orthop. 1999; 115: 166-174. 
[15]. Sherwood KH, Nurchg JG, Thompson WJ. Closing anterior open bites by intruding molars with titanium miniplate anchorage. Am J Orthod Dentofacial Orthop. 2002; 122: 593-600

[16]. Miyawaki S, Koyama I, Inoue M, Mishima K, Sugahara T, Takano-Yamamoto T. Factors associated with the stability of titanium screws placed in the posterior region for orthodontic anchorage. Am J Orthod Dentofacial Orthop. 2003; 124: 373-378.

[17]. Park HS, Bae SM, Kyung HM, Sung JH. Micro-implant anchorage for treatment of skeletal Class I bialveolar protrusion. J Clin Orthod. $2001 ; 35: 417-422$.

[18]. Bae SM, Park HS, Kyung HM, Kwon OW, Sung JH. Clinical application of micro-implant anchorage. J Clin Orthod. 2002; 36: 298-302.

[19]. Costa A, Raffini M, Melsen B. Miniscrews as orthodontic anchorage: a preliminary report. Int J Adult Orthod Orthog Surg. 1998;13: 201-209.

[20]. Yao CC, Wu CB, Wu HY, Kok SH, Chang HF, Chen YJ. Intrusion of the overerupted upper left first and second molars by miniimplants with partial-fixed orthodontic appliances: a case report. Angle Orthod. 2004; 74: 501-507.

[21]. Mittal R, Patil AK, Ganeshkar SV. Correction of Deep Overbite with Mini-Implants in Adult Patients. The orthodontic cyber journal. 2009. Taken from [http://orthocj.com/2009/01/correction-of-deep-overbite-with-mini-implants-in-adult-patients/] Accessed on $26^{\text {th }}$ May 2015.

[22]. Ozsoy OP, Ozcirpici AA, Veziroglu F, Cetinsahin A. Comparison of the intrusive effects of miniscrews and utility arches. Am J Orthod Dentofacial Orthop 2011 ;139: 526-32.

[23]. KrishnaNayak US Goyal V., Godhrawala F, Saxena R. Comparison of skeletodental changes occurring during deep overbite correction with mini-implant anchorage system and the utility arches reinforced by a transpalatal arch. JIOS 2011; 45(1): 9-14. 